Article

\title{
Increasing Production and Eliminating Waste through Lean Tools and Techniques for Halal Food Companies
}

\section{Malihe Manzouri ${ }^{1}$, Mohd Nizam Ab-Rahman ${ }^{1, *}$, Che Rosmawati Che Mohd Zain ${ }^{2}$ and Ezad Azraai Jamsari ${ }^{3}$}

1 Department of Mechanical and Materials Engineering, Faculty of Engineering and Built Environment, National University of Malaysia, Bangi 43600, Malaysia;

E-Mail: mmanzouri@yahoo.com

2 Putra Business School, University Putra Malaysia, Serdang 43400, Malaysia;

E-Mail: cherosmawaticmz@gmail.com

3 Faculty of Islamic Studies, National University of Malaysia, Bangi 43600, Malaysia; E-Mail: ezad@ukm.edu.my

* Author to whom correspondence should be addressed; E-Mail: mnizam@eng.ukm.my; Tel.: +60-38921-6449.

External Editor: Marc A. Rosen

Received: 27 September 2014; in revised form: 28 November 2014 / Accepted: 2 December 2014 / Published: 11 December 2014

\begin{abstract}
Major businesses around the world have been trying to reduce the total cost and wastes across their supply chain to remain competitive in the expanding global market. Hence, a collection of reliable tools and techniques are vital for decreasing costs and wastes and for providing effective services for customer demands. Given that lean concept attempts to decrease costs and wastes, this study aims to identify the effective lean tools required for eliminating wastes in the supply chain. Because of the large number of consumers and the global market of Halal products, this study focuses on Halal food supply chains. Out of the questionnaires distributed to 300 Halal food firms in Malaysia, only 61 usable replies were obtained. The results showed that demand collaboration, continuous improvement, and inventory management practices are the most important tools in Lean Supply Chain (LSC) implementation. In addition, the results indicated that only a small percentage of Halal food companies are implementing LSC. Malaysia is an important Halal food producer in the word, but has low level of LSC implementation among its Halal food producers. LSC is a new concept that needs more effort to be understood and implemented.
\end{abstract}


Keywords: waste management; lean supply chain; lean practices; Halal food companies; supply chain; barriers

\section{Introduction}

The impact of Lean Practices (LP) on business success cannot be ignored. Lean tools and techniques have enabled companies to be more flexible and more profitable. Several companies invest in the implementation of LP to remain competitive. Demeterand Matyusz [1] believe that lean production is the most popular investment choice among companies. The process comprises pull production, quality development, process focus, continuous improvement, value stream management, and worker empowerment. The objective of LP is to satisfy customer demands on the highest possible level through waste reduction [2,3]. Elimination of wastes can be considered in the human resources, design, production processes [4,5] and activities, distribution, and inventory sections. If several kinds of wastes can be eliminated, how do companies practice the fundamental principles of lean to build adaptive, flexible, and creative supply chains? What are the appropriate tools and techniques of the lean supply chain?

Supply chain professionals are working on means to decrease wasted effort and non-value activities across the supply chain. According to the concept of LP, implementing its tools and techniques help minimize such wasted effort [6]. During the first steps, supply chain partners should understand the lean concept, and then implement its practices through high levels of collaboration and cooperation.

Most articles on LP focus on the implementation of systems, such as just-in-time (JIT), total quality management (TQM), total preventive maintenance programs, human resource management, value stream mapping, and vendor development, as well as their impact on operational performance [1,2,7-9]. Fewer studies investigate the implementation of the lean concept in the supply chain, and identify the most important tools and techniques that carry out the objectives of the lean concept in the supply chain. Thus, this study aims to determine the ways to implement the lean concept in the supply chain, and to come up with effective LSC practices. Although LPs are becoming popular techniques for productivity improvement, companies are still not certain of the cost of its implementation and the tangible and intangible benefits they may achieve. Most of these companies fear that implementing lean practices is costly and does not produce benefits [10]. Hence, understanding these advantages can facilitate the implementation of the tools and techniques of LPs.

To date, the more efficient operation in Halal food supply chains has gained more attention because of increasing competition in the developing market for Halal products. The large numbers of Muslims (1.57 billion) in the world [11] creates a major opportunity in trading Halal products in the global business market. Halal producers attempt to introduce their products as a symbol of quality and excellence. As a result, they can market their products not only to Muslims, but also all over the world. Halal food is the most important section of Halal products, not only because it is part of Islamic law, but also because of its emphasis on cleanliness and health. The development of Halal food processing technology makes simple food processing complex because producers must understand the religious and scientific basis of Halal food requirement. Managing these requirements makes the Halal food chain complex. Halal food producers must only choose suppliers who can provide Halal food requirement. To fulfill Halal rules, suppliers require 
specific equipment, which need time and cost. Therefore, this study investigates how the lean concept can be adapted in manufacturing Halal food products to improve the overall performance of companies.

This study has four sections. The first section deals with reviewing the related literature on LSC, with particular emphasis on the concurrent implementation of strategic initiatives. The second section describes the survey methodology used to obtain data in this study. The third section explains the results of the survey and discusses the findings to clarify the objectives of this research. The last section presents the conclusion and proposes future research areas.

\subsection{Lean Supply Chain Practices}

The term "lean" is a concept that implies a series of activities or solutions for eliminating waste and non-value-added operations [12,13]. MIT was the first to use the term for the interpretation of a new production system that had recently been used by the Japanese [14]. Because mass production results in much waste and non-value activities, the Japanese utilize a new system that focuses on reducing waste and preserving value with less work. Japanese producers are more productive compared to Western producers, and the former dedicates more energy to a system that aims to remove waste at all levels [15].

The lean concept has been widely used in production systems [2,8,12,15-19]. Womack [20] defines lean production as a system that creates value-added by using less of every input, which is based on the waste concept of the Japanese [21]. Demeter and Matyusz [1] emphasize that lean production or lean enterprise emerges when the company implements lean development, procurement, manufacturing, and distribution together. Lean production philosophy and concept are highly considered due to its global superiority in cost, quality, flexibility, and quick response [22]. Several researchers emphasize the importance of implementing lean production systems. In addition, if a company ignores lean production strategy, the company would not stand a chance against the current global competition in terms of higher quality, faster delivery, and lower costs [10,23-25].

Scholars and practitioners discuss extensively lean production practices [2,10,26-30]. As proposed by different studies, several LPs exist (Table 1) with multiple names, overlap with other tools, and have different methods of implementation. Shahand Ward [2] introduce 22 lean production practices. They categorize these practices into four bundles associated with Just-in-Time, Total Quality Management, Total Preventive Management, and Human Resource. Nordin, Deros, Wahaband Ab-Rahman [10] highlight that LPs can be categorized according to the area of implementation, such as internally and externally-oriented LPs. Panizzolo [31] points out many companies find difficulty in implementing lean techniques that concern with external relationships with suppliers and customers. LPs can be divided into six areas, namely, process and equipment, manufacturing, planning and control, human resources, product design, supplier relationships, and customer relationships. The first four areas are grouped as internal-oriented LPs, whereas the supplier relationships and customer relationships are under the external-oriented LPs [10,31].

Liker and Meier [29] categorize the purpose of LPs into three groups, which are problem identification and elevation, analysis to the causes of problems, and solutions. When waste and problems are identified, people find the solutions, and continuously improve the system [32] reveals all lean tools are developed to support the implementation of lean principles and overall organization strategy. Hence, a company should implement almost all the tools in the lean toolbox to become successful [33]. 
Table 1. Lean production practices [2,10,26-29,37-40].

\begin{tabular}{ll}
\hline Process and equipment & \\
\hline Continuous reduction of cycle time & Setup time reduction \\
Cellular manufacturing & Simplify the product design \\
Error proof equipment & $\begin{array}{l}\text { Rigorous preventive maintenance } \\
\text { Progressive use of new process technologies }\end{array}$ \\
Order and cleanliness in the plant & $5 \mathrm{~S}$ \\
\hline Manufacturing planning and control & \\
\hline Leveled production & Synchronized scheduling \\
Small lot sizing & Visual control of the shop floor \\
Kanban/production management & Mistake-proofing (poka-yoke) \\
\hline Human resources & \\
\hline Worker training & Team decision making \\
Cross functional team & Expansion of autonomy and responsibility \\
Employee involvement in continuous quality improvement programs & Kaizen \\
\hline Customer relationship & \\
\hline Information sharing & Customer involvement in product design \\
Customer involvement in quality program & JIT link with customer \\
Flexibility on meeting customer requirement & \\
\hline
\end{tabular}

Nordin et al. [10] highlight the need for companies to apply basic lean techniques at the start of implementing LPs, and to implement more advanced practices to further develop lean culture and sustainability when the change process has stabilized. The 5S, standardized work, elimination of wastes, visual control, kanban, poka-yoke, and single minute exchange of dies are suggestions to be implemented at the first stage [32-34].

Similar to the lean production system that finds all kinds of waste in the company, the lean supply chain (LSC) identifies and attempts to eliminate all types of wastes in the supply chain [12]. In managing the supply chain, companies focus on activities that provide the raw materials, produce the final products, and deliver to the end customers in a cost effective manner. However, LSC focuses on all wastes that may happen during each step in the supply chain, and attempts to reduce waste [35]. Plenert [36] highlights supply chain management (SCM) as a total system requiring integration and optimization, which are accomplished through lean tools and techniques. Hence, a combination of the LPs and the SCM philosophy can create successful and dynamic synergy. LSC is a strategy model for customer-supplier relationship that focuses on partnership as collaboration. According to Phelps et al. [37], LSC provides value to customers by optimizing the performance of the whole supply chain as a system. Reducing inventory and cost and improving customer satisfaction are the most important aspects of LSC. For the integration of the lean concept and SCM, the main components of LSC are the lean enterprise, warehouse, transportation, and retailer. Lehtinen and Torkko [21] define the characteristics of LSC into seven different areas. These areas are (1) nature of the competition; (2) basis of the source decision; (3) supply structure; (4) role of suppliers; (5) supplier development; (6) data interchange and interaction; and (7) production principles. According to this classification in implementing LSC, the competition is not among the members of a supply chain, but among the supply chains. The number of sources should be decreased as 
much as possible. For example, the number of suppliers should be kept low and stable. Suppliers are highly involved in designing new products and processes, and production systems are flexible and just in time (JIT).

Compared with implementing lean production (or enterprise), adapting LPs in the supply chain is more complex and extensive. At first, all members of a supply chain must implement lean enterprise and identify new methods to improve their internal activities (i.e., improve quality, inventory, transportation, and costs), and then generalize their improvements in all tiers of the supply chain. Thus, all tools and techniques should be adapted based on the whole supply chain benefits. All value-added activities and non-value activities are defined based on the advantages of all supply chain partners. In implementing LSC, companies pass seven important steps. These steps are (1) develop system thinking; (2) understand customer value; (3) value stream mapping; (4) benchmark best practices; (5) design to manage demand volatility; (6) create flow; and (7) measure performance metrics [41]. In addition, companies need to pass three steps in managing network process and design. These steps are (1) integration of supply chain function within the enterprise; (2) integration of internal and external activities with supply partners; and (3) creation of an internet connection among supply partners to make a single virtual enterprise [42].

A comparison between LSC and conventional supply chain practices highlights the numerous changes in operational and relational issues when companies switch from conventional operation to the LSC model [43]. According to this illustration, operations have been reduced dramatically, and their structures have been changed to a clustered model. This change makes it possible to pursue many parallel activities at the same time with lower resources. Based on this definition, if the procurement personnel (as an important resource) are limited, the cost and time of activities will decrease. In addition, the outsourcing processes changed from cost-based to strategic. The nature of interaction between partners changes from adversarial to cooperative, and the supplier contract length is increased. Instead of intensive inspection of product quality, companies design their products based on the comments of their customers and suppliers. Hence, rather than inter-organizational issues, external issues have critical roles in implementing LSC. Although the status of the LPs has been widely discussed in the literature, studies in terms of LSC practices are limited. Clear understanding is necessary for the effective tools and techniques in adapting LSC. Hence, this paper aims to identify the most important tools in implementing the lean concept in the supply chain.

In reality, only a few companies are successful in its implementation of LPs despites its benefits [44-46]. Literature reveals barriers and issues relating to these failures. Misunderstanding the concept and purpose of LPs and availability of resources (time, skilled workers, and costs) are most frequently reported in lean literature [47-49]. One reason behind this lack might be cultural differences that arise in transition, or the translation of the lean principle and techniques during implementation phases [50,51]. The lack of resource availability (time, skilled workers and costs) is reported to be a very serious obstacle in its adoption [32,52-55]. Lack of top management support for change is another key problematic issue reported in the literature $[47,49,56]$. Since all activities in a company, from planning to implementation, are conducted under the supervision of senior managers, the absence of their support will cause implementing lean tools and techniques to fail [57].

These barriers make it vital to demonstrate the effective benefits of adapting LPs to persuade companies in its implementation. Since lean concept originated in automotive industries, benefits have been observed and documented in these industries [32]. For instance, these industries reported decreased lead times for customers, reduced inventories for manufacturers, improved knowledge management, and 
more robust processes. Apart from automobile industries, lean implementation benefits have been observed in other industries. Al-Sudairi [58] reports that implementing LPs reduces material flow time in the construction section. Lian and Van Landeghem [59] show improvements in storage and transportation of animal foods when they implemented LPs. Zheng et al. [60] note the reduction in factory variability when LPs are applied. Domingo et al. [61] highlight that material flow is improved in the assembly line of a Spanish Bosch factory when LPs are implemented. Grewal [62] reveals that when LPs are implemented in a small manufacturing firm, the cycle time is reduced by $33.18 \%$, changeover time is decreased by $81.5 \%$, lead time is reduced by $81.4 \%$, and value-added time is reduced by $1.41 \%$. Seth et al. [63] claim that implementing LPs in the Indian cottonseed oil industry reduces or eliminates waste in the processes.

\subsection{Halal Definition}

Similar with all other religions, Islam prescribes or prohibits certain behaviors, including the regulation of the consumption behavior of its followers. Therefore, Muslims are likely to make purchase decisions influenced by Islam. Muslims have the obligation to assure that the goods they consume are true manifestations of Islamic principles, known as Halalan Tayyiba. "Halal" specifies products permissible or allowed by Islam, whereas "Haram" refers to forbidden, unlawful, or illegal products. Halal emphasizes the safety, hygiene, and wholesomeness of not only the final products, but also their methods of preparation [64]. From the perspective of Muslims, Halal is an essential way of life. Additionally, Halal is not solely confined to the types of food a Muslim is allowed to consume. This term can be applied to cosmetics or even pharmaceuticals, shampoo, soap, and detergent.

Malaysia is the only country in the world with a government that provides full support in promoting the Halal certification process on products and services [65]. All companies that attempt to produce Halal products must be approved with a Halal certificate. This certificate provides assurance to all Muslim consumers that this product fulfills the Syariah (Islam) law. Moreover, this certificate guarantees the safety and quality of products for non-Muslims consumers.

Halal-certified sellers must use a Halal logo on their products. This practice provides an avenue for producers to indicate to their target consumers that their products meet the Islamic standard. Halal certification is a significant advantage to particular producers against their competitors [66]. Besides, Malaysia is a pioneer in the development of Halal standards. The following examples further demonstrate Malaysian involvement in the promotion of Halal. MS 1500:2009 is developed for Halal Food in terms of production, preparation, handling, and storage. MS 2200 is developed for cosmetic and personal care. MS 1900:2005 is developed for quality management systems (requirements from Islamic perspectives). MS 2300:2009 is developed for value-based management system (requirements from an Islamic perspective). MS 2400 series on Halalan-Toyyiban Assurance Pipeline is the management system requirement for transportation, warehousing, and retailing. MS 2424:2010 is developed for Halal Pharmaceuticals [65].

\subsection{Halal Food Industry}

Food is a vital component for livelihood. Thus, Halal foods are the important parts of Halal products. Halal rules are not only concerned on safety, hygiene, and wholesomeness of the foods, but also provide 
an excellent platform for healthy eating. Additionally, the place, equipment, and process of slaughtering and storing animals most focus on Halal rules. Halal food products do not contain (1) any part or product of non-Halal animals; (2) any part or product of Halal animals not slaughtered in accordance with Shariah (Islamic law); (3) any ingredient that is Najs (unclean, as defined by Shariah); (4) physical, chemical, or biological/microbial hazards; and (5) any human part or derivative. Nowadays, Halal food products are familiar to non-Muslims because of humane animal treatment concerns. The perception that Halal foods are healthier and safer fuelled this familiarity. Therefore, the consumption of Halal products is no longer a mere religious obligation, but is a standard [64]. Muhammad [67] highlights that in the Philippines, non- Muslims look for Halal foods because they perceive these products safe, healthy, and good for the body.

In Malaysia, $62 \%$ of the population is Muslim, $24 \%$ are Chinese (mostly Buddhist), and $8 \%$ are Indians with Hinduism as their main religion. Therefore, the large part of the food market of this country provides Halal food products. In addition, 62\% of all Muslims live in Asia [11], which provides Malaysia the opportunity to be considered as a Halal hub among Muslim countries in the region. As a result, the Malaysian government aims to establish this country as a global Halal hub for the promotion, production, and transportation of Halal food products to Muslims all over the world [68]. The Malaysian government developed the first Halal Standard (MS 1500:2004) to help food companies reach Halal procurement. This standard provides practical guidance for the food industry on the preparation and handling of Halal food (including nutrient supplements). Moreover, this standard guides the food industry to meet the basic requirement for Halal food product, trade, or business in Malaysia [65].

A supply chain includes all independent companies that closely work together to manage flow of products and information to satisfy end customer requirements at lowest possible costs. The food supply chain starts from the farm where the animals are kept or where the seeds are grown. The chain continues in the factory, where all processes are done to manufacture the products. This process is followed by warehousing and distributing of final products to the end customers. In accordance with the rules and regulations of Islam, the entire supply chain of food products from seed to fork must pursue the Halal concept until the final product is called Halal. Thus, all materials used to produce Halal food should be Halal, and all machineries should not be contaminated by non-Halal items. Therefore, the Halal food supply chains are essential for Muslims because non-Muslims manage most parts of Halal supply chains.

The importance of food among Halal products makes it necessary to find out the extent to which Halal suppliers attempt in implementing quality systems, such as LPs, to increase their profitability and decrease their waste and non-value activities. Therefore, this study aims to investigate the implementation of LPs in the Halal food supply chains, which are mostly necessary, and to identify how barriers impede in these important practices.

\section{Materials and Methods}

This study considers the importance of Halal food products in the world and the unique contribution of Malaysia in the procurement of these products. Consequently, the Malaysian Halal food manufacturers were selected as the target population of this study. The list of companies encompasses bakeries, fruits and vegetables, beverages, seafood, dairy, grains and oilseeds, beef and chicken products, and other food 
components. In this study, the companies involved ranged from small to large. This range was applied to obtain a holistic view of LSC implementation in the Halal food industry.

A questionnaire was developed based on the lean and SCM implementation concepts and practices. A set of LSC tools was designed based on the Srinivasan [41] as well as definition of the LSC implementation and lean concept (Table 2) of Demeter and Matyusz [1]. Value-added activities are considered as tools to examine customer requirements in the whole supply chain because understanding customer value is important to continue improvement in the waste reduction system $[69,70]$. Demand variation and order fluctuation are the common difficulties encountered in strategy management of each organization, which can be managed through supply chain collaboration. Managing demand volatility not only improves organizational performance, but also recovers the outcome of the whole supply chain. In this regard, demand collaboration and signal are considered LSC implementation tools to understand the clarity of demand across the supply chain.

Table 2. Designing LSC practices based on LSC definition and SCM theories.

\begin{tabular}{lll}
\hline LSC Implementation [41] and [1] & Designed LSC Practices & Adapted Theories of SCM \\
\hline \multirow{2}{*}{ Understand customer value } & $\begin{array}{l}\text { Value-added activities } \\
\text { Eliminate wastes }\end{array}$ & $\begin{array}{l}\text { Game theory; Organizational } \\
\text { learning theory }\end{array}$ \\
\hline Design to manage demand & Demand signal & Strategic choice; \\
volatility & Demand collaboration & Organizational learning theory \\
\hline Create flow & Data standard & Resource-based view theory \\
\hline \multirow{3}{*}{ Measuring performance metrics } & Continuous improvement/ & Game theory; Organizational \\
& Change culture & learning theory; \\
& Employee involvement & Social capital theory \\
\hline \multirow{4}{*}{ Benchmark best practices; } & Company product standard & Resource based view \\
Lean development & Industry product standard & Resource dependent theory \\
& Planning and production process & $\begin{array}{l}\text { Institutional theory } \\
\end{array}$ \\
& standardization & Strategic choice \\
& Sales and operations planning & System theory \\
\hline
\end{tabular}

Sharing information has a critical role in managing the supply chain. Therefore, all tiers of a supply chain need to use a similar data format to share their information and to use their output data. Using the industry standard data format makes data exchange possible across the whole supply chain. Hence, using data standard was considered as another tool of LSC adaption. Each tier of a supply chain needs a performance measurement system to monitor organizational functions. Therefore, a continuous improvement system is required to monitor organizational performance. Based on the theory of network [71] in the SCM, maximizing the organizational performance is possible by creating a blend of weak and strong ties in the supply chain, which can be achieved by benchmarking from successful companies. This goal can be accomplished at the level of planning, designing, producing, operating, or sales, depending on the weaknesses of the company. Besides, inventory management was considered as another tool in adapting LSC because of its importance in the supply chain operation, thereby helping the organization maintain a competitive advantage. Any problem in managing inventory, either excessive product stock or backlog, causes difficulties in customer order, product storage, or additional costs for transportation. 
To achieve a more detailed description of these techniques, related SCM theories were involved in designing the questionnaire construct (Table 2). According to the theory of strategic choice, the unique blended strategies beyond the individual firm should be applied in the SCM strategy decision-making. Thus, the supply chain, as the primary driver, is considered in all strategic decision-making processes in each tier of a chain. Therefore, in implementing LSC tools (Table 2), the decision must be made based on the whole supply chain benefits. The resource-based view theory [71] suggests that each tier can earn competitive advantages using valuable, priceless, and rare resources of its supply chain. According to this point of view, the supply chain is an inimitable competitive weapon, which can provide capability for product and process improvement. Moreover, institutional theory suggests sharing of organizational recipes among supply partners. Therefore, using supply chain resources and sharing organizational recipes make it possible for companies to standardize the planning, producing, and stock management processes across the whole supply chain. In addition, planning sales and operations in companies can use online tools available to all supply chain partners. More importantly, in developing new products, a high proportion of shared parts from other product lines of supply chain partners can be used. This strategy not only decreases designing time, but also avoids wasting time in making new tools and production line for these shared products because they were already produced in the other tier of the supply chain. Moreover, since the supply chain resources are shared, supply chain partners can use global or industry standard data format in exchanging products, availability, and sales-related data.

Game theory [72] suggests that a trustworthy relationship and mutual relation impede supply partners to pursue individual benefits instead of supply advantages. Organizational learning theory [73] implies sharing of knowledge and experiences among supply chain partners. Thus, if companies actively perform collaborative practices with their suppliers and customers as well as share their knowledge and experiences, non-value-added activities and numerous kinds of waste would be eliminated dramatically [74]. Social capital theory [72] suggests that joining for problem solving and sharing goals, experiences, information, and values among supply chain partners can improve organizational performance. Thus, all partners can establish a continuous improvement culture across the whole supply chain.

Since employers carry out all processes and activities, cooperation and coordination play an essential role in implementing LSC practices. Undoubtedly, implementing a new system takes time. Additionally, implementation is difficult to establish. Therefore, employers should not only be trained, but also encouraged and supported to believe they are valued assets.

Throughout the construction of the questionnaire, discussions were held with three food experts in the field of lean and SCM to check on the clarity of the questions and appropriateness of the proposed scale. These experts were chosen based on their willingness to participate and their level of experience (more than 10 years) in implementing lean and SCM initiatives in the food industry. The comments and feedback given were very useful in enhancing, amending, and improving the questionnaire. Based on the suggestions of the experts, the questions related to the "LSC tools" were completed.

This section is categorized by 12 parts (Table 3). Each part consists of four subsets (A, B, C and D). Each subset identifies the level of implementation of the main part. Thus, A shows "no implementation," B shows little implementation, C shows "extensive implementation," and D shows "complete implementation." To clarify the notion and aim of each item, the subset explains the possibility of level of implementation, instead of using terms, such as "no implementation," "little implementation," 
"extensive implementation," and "complete implementation." Experts believe that this style provides an opportunity for the respondent to understand fully the items and avoid possible misunderstanding.

Table 3. LSC practices.

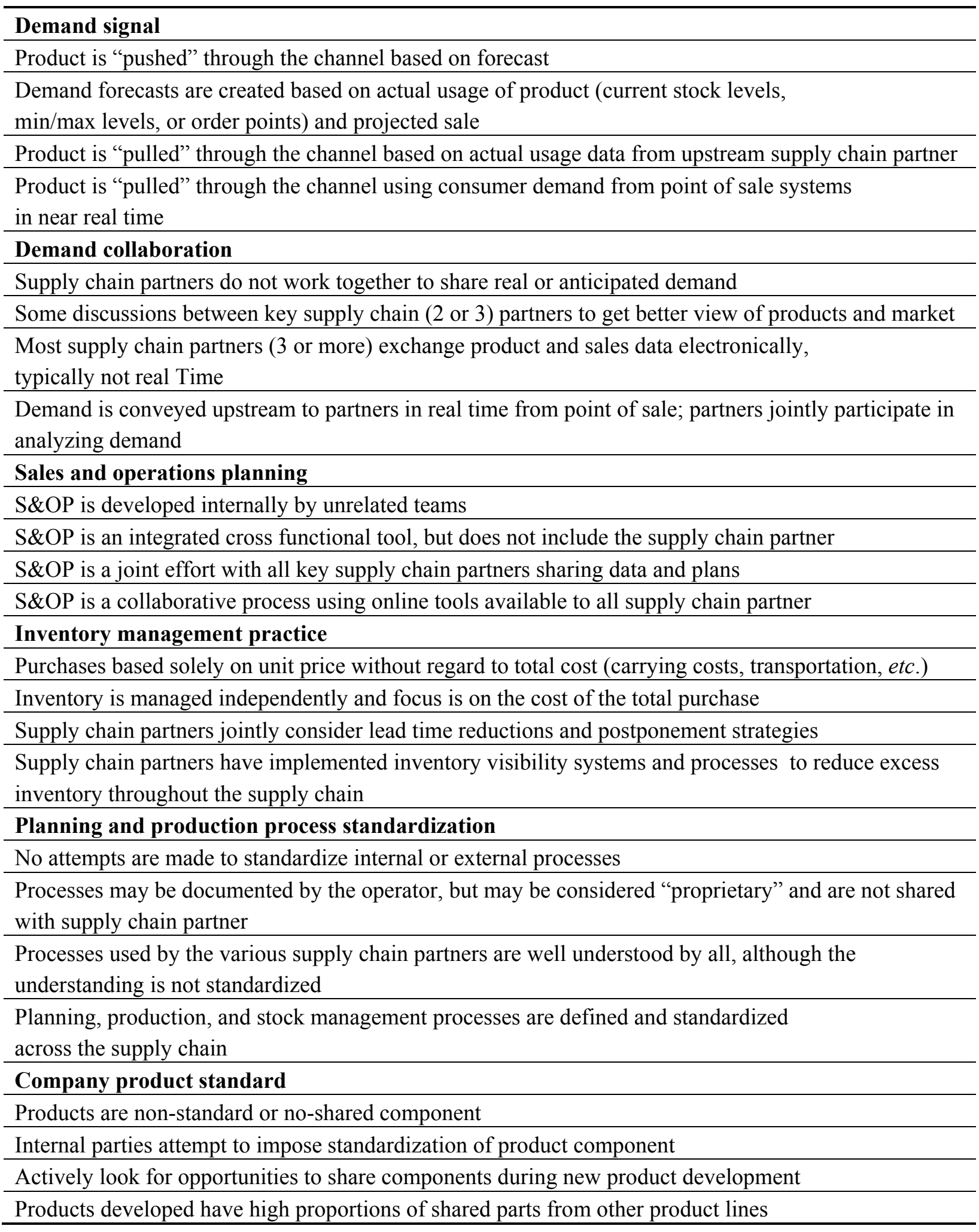


Table 3. Cont.

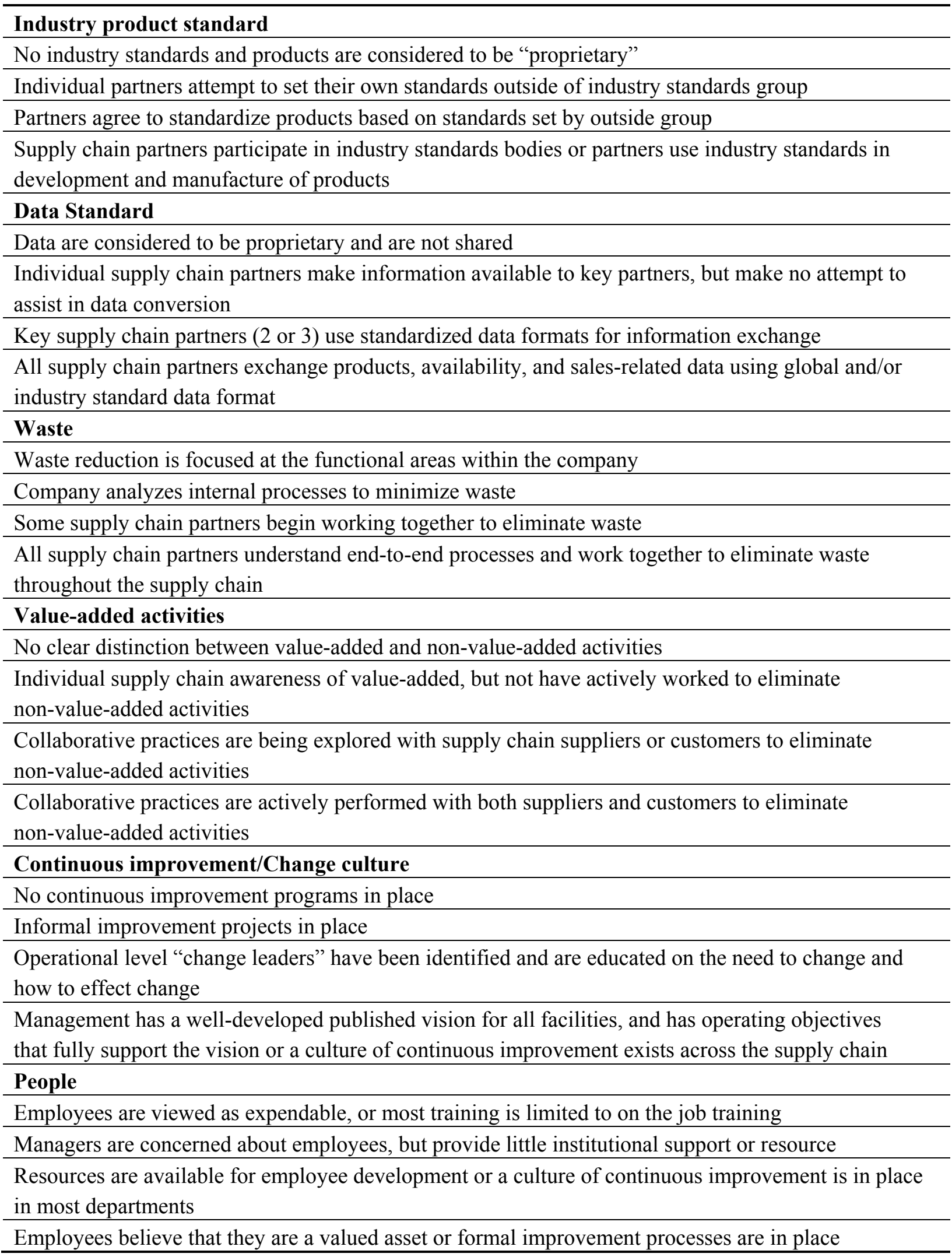

The questionnaire was distributed to Halal food manufacturers who participated in the food festivals held in Kuala Lumpur and Penang, Malaysia in 2011 and 2012. Companies from all over Malaysia participated in these festivals. Collecting several responses was difficult because the population of this 
study is limited to Halal food companies in Malaysia. On hundred Halal food companies asked to participate in this study answered the questionnaire appropriately. Just 100 companies answered the questionnaire appropriately. This response rate is acceptable based on previous studies on lean and SCM implementation (i.e., $[10,75]$ ) and the rate of used constructs [76]. The personnel selected to answer the questionnaire were managing directors, managers of planning or strategy, production, marketing or sales, supply chain, quality and engineering departments. These managers are involved in the implementation of LSC in their respective firms.

Respondents were asked to participate in a face-to-face interview and answer the questionnaire. Face-to-face interviews clarified ambiguities and made the questionnaire fully understandable. The questionnaire comprised three parts. These parts are (1) background information of the firm, including year of establishment, ownership, number of employees, and quality system certification; (2) LSC practices implementation; and (3) respondent information, including job title, department, and years of service.

The method of Johnston et al. [77] was adopted in this study to estimate the likelihood of a non-response bias. Responses to LSC tool variables of four groups of participants in two different Halal food festivals (Penang and Kuala Lumpur) were compared among respondents who replied immediately and respondents who sent their replies after the festivals by mail. The average responses in each case varied by less than $1 \%$, which suggests that values would not change significantly if more sample had responded. A combination of face validity and convergent validity (in Smart PLS software) was used to estimate the appropriate reflection of the measurement items of LSC practices. According to Johnston, McCutcheon, Stuart and Kerwood [77], this method uses alternative ways of judging multiple-item consistency instead of Cronbach's alpha. Therefore, in addition to Cronbach's alpha, tests were conducted on the reliability of individual items that make up the measures, the composite reliability (CR) of the items as a group, and the average variance extracted (AVE) from the construct (LSC tools) of the items (Table 4). Malhotra [78] suggests that a value of 0.6 or less from 0 to 1 in Cronbach's alpha test indicates unsatisfactory consistency reliability. The value of Cronbach's alpha of the LSC practice items in this study was measured via Smart PLS software (Table 4). The results show a high level (0.91) of consistency among items.

Table 4. Convergent validity of LSC variables.

\begin{tabular}{ccc}
\hline $\mathbf{C R}>\mathbf{0 . 7}$ and $\mathbf{C R}>$ AVE & AVE $>\mathbf{0 . 5}$ & $\mathbf{C A}>\mathbf{0 . 7}$ \\
\hline Composite reliability & AVE & Cronbach's alpha \\
0.9313 & 0.5383 & 0.9171 \\
\hline
\end{tabular}

The loading factor was used to assess the reliability of individual items of the LSC practices [77] suggests that 0.7 is the minimum level for item loading. Out of the twelve items of LSC practices, four items were below this threshold at $0.63,0.4,0.56$, and 0.64 (Table 5). CR assesses inter-item consistency, which must be at a minimum value of 0.7 . The results in Table 4 demonstrate acceptable performance based on this principle.

The third standard of reliability is the AVE of the LSC practices (construct) that exceeds 0.5. This values shows that the items share at least half of their variance with the construct. These results reveal the acceptability of this standard. CR $>$ AVE is another standard of reliability, which was achieved in this study (Table 4). Four items demonstrate loading factors (Table 5). According to [77], these values 
are not extremely low to render the measure of this construct as unacceptable. Thus, the items that were selected to define LSC practices are consistent and reliable.

Table 5. Factor loading of LSC practice items.

\begin{tabular}{ll}
\hline LSC practice & Factor \\
\hline Demand signal & 0.6351 \\
Demand collaboration & 0.3674 \\
S\&OP planning & 0.7383 \\
Inventory management practice & 0.6507 \\
Planning and production process standardization & 0.8567 \\
Company product standard & 0.7469 \\
Industry product standard & 0.6417 \\
Data standard & 0.8146 \\
Waste & 0.8698 \\
Value-added activities & 0.7615 \\
Continuous improvement/Change culture & 0.7731 \\
People & 0.8072 \\
\hline
\end{tabular}

\section{Results and Discussion}

Data from the questionnaires show that the production of Halal food products is popular among local companies in Malaysia. The majority of participating companies (Figure 1) are local companies and few foreign companies or joint ventures.

Figure 1. Type of ownership.

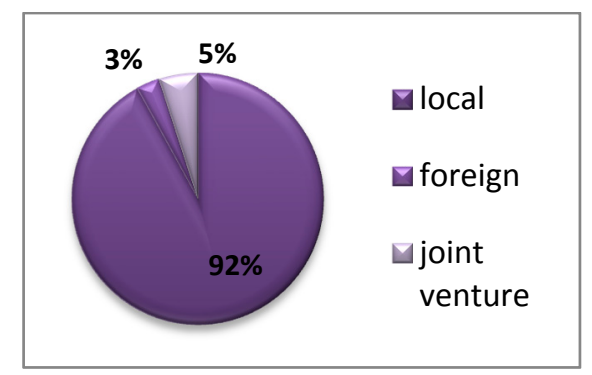

The size of companies (Figure 2) was classified based on the number of full-time employees (according to the SEMcorp, Kuala Lumpur, Malaysia, 2012 definition) because several participants did not indicate their annual turnover. The highest percentage of participating companies (48\%) belonged to small companies that have less than 50 full-time employees. The rate of medium (26\%) and large (26\%) companies are identical. Table 6 shows that Halal food production is the main domain of small companies because majority of Malaysians are Muslims who intend to produce Halal food products. Certain small companies that produce Halal products have definite consumers. Chi-square test was employed to understand the relationship between company size and the possibility of implementing LSC tools. The results show that the size of companies facilitates the implementation of human resource (people) activities, value-added activities, planning, and production process standardization. The possibility of implementing these tools increases with the growing size of companies. Large companies 
can adapt to these tools easily because they have more financial resources. However, the implementation of other tools is not facilitated in large companies, which could be attributed to lack of understanding of LSC tools and management support.

Figure 2. A: Number of Employees.

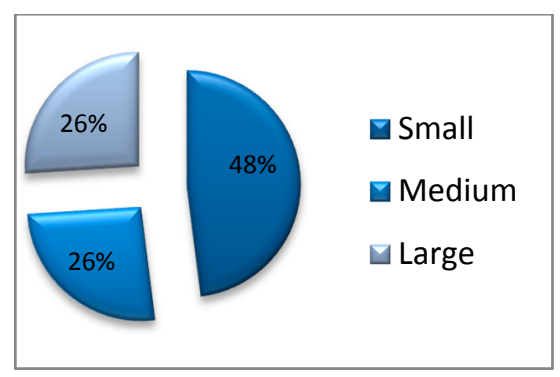

Table 6. Size of company and ownership.

\begin{tabular}{cccc}
\hline & Small & Medium & Large \\
\hline Local & $45 \%$ & $23 \%$ & $24 \%$ \\
Foreign & $2 \%$ & 0 & $1 \%$ \\
Joint-venture & $1 \%$ & $3 \%$ & $1 \%$ \\
\hline
\end{tabular}

About $18 \%$ of respondents did not have quality system certification. Thus, majority of Halal food companies have yet to apply LSC. Figure 3 shows more than $74 \%$ of respondents were certified by HACCP. Around 23\% of the respondents were certified by ISO9001, and 26\% was certified by ISO22000. A small number of participants registered other types of quality certificates. About $46 \%$ of the responding companies had one quality certificate. Only $2 \%$ of the companies had four quality certificates. Therefore, the number of quality-certified companies in Halal food industries in Malaysia is extremely low, which is a matter that requires attention. This situation could be attributed to the small number of Halal food companies in Malaysia. Small firms in Malaysia are registered as sole proprietorships and are managed by the owner [79]. The owner conducts decisions regarding the implementation of a new system because he or she determines the development of the business.

Figure 3. Quality system implementation (\%).

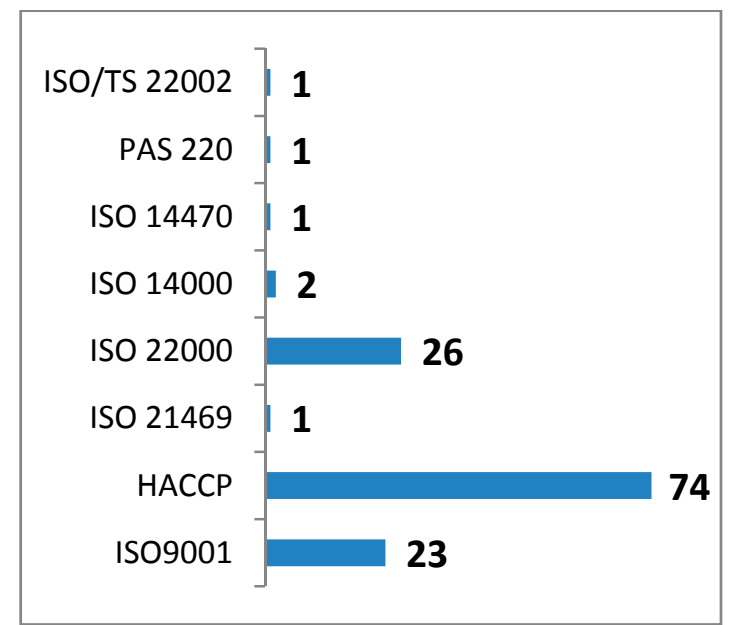


Small businesses often have limited resources [79,80], especially new start-up companies that are highly dependent on the ability of the owner to generate resources. These firms are not successful in implementing new systems because any change requires additional capital or resources. The structure of these firms is often flat and informal. Employees can function as generalists because there is no clear demarcation of tasks. Hence, the implementation of a new system is not such a difficult task because owners will have more flexibility to adapt to changes in the environment due to their size and informal structure. However, Table 7 shows that the rate of quality system implementation in large Halal food companies is not interesting. This situation can be attributed to the lack of awareness of quality system because these companies do not often face top manager decision and capital problems. These companies are not aware of the importance of these quality systems, and their customers are not aware of their benefit and existence.

Table 7. Quality system and company size.

\begin{tabular}{cccc}
\hline & Small & Medium & Large \\
\hline ISO 9001 & $5 \%$ & $8 \%$ & $10 \%$ \\
HACCP & $31 \%$ & $22 \%$ & $21 \%$ \\
ISO 21469 & $1 \%$ & 0 & 0 \\
ISO 22000 & $3 \%$ & $11 \%$ & $12 \%$ \\
ISO 14000 & 0 & $1 \%$ & $1 \%$ \\
ISO 14470 & 0 & 0 & $1 \%$ \\
PAS 220 & 0 & 0 & $1 \%$ \\
ISO/TS 22002 & 0 & 0 & $1 \%$ \\
\hline
\end{tabular}

The chi-square test was used to understand the influence of quality system application on LSC tool implementation. The results show the relationship between the adoption of ISO 9001 system and the possibility of implementing LSC tools. The companies that adopted ISO 9001 at the highest range are most successful in implementing LSC tools. By contrast, the adoption of HACCP and ISO 22000 and the implementation of LSC tools are not correlated. ISO 9001 standard helps companies to meet customer needs while meeting product quality requirements. This standard is in the same line of LSC tools because its aim is to improve overall performance. Thus, non-LSC companies may apply ISO9001 in preparation for LSC implementation.

This study shows that demand collaboration practice, which has a mean score of 2.96 (Figure 4), was implemented at the highest level during the adoption of LSC. Table 8 shows how these companies implemented different levels of LSC practices (A to D). About $41.7 \%$ of these companies have fully implemented demand collaboration, in which demand is conveyed upstream to partners in real time from the point of sale (POS). The partners jointly participate in demand analysis. About $22.9 \%$ of these companies, which are mostly supply chain partners (three or more), electronically exchange product and sales data, but not in real time. About $25 \%$ of these companies are not successful in managing their supply chain demand. Only the key supply chain (two or three) partners make the discussion to obtain a better view of products and markets. However, $10.4 \%$ of the participants do not share real or anticipated demand. To achieve LSC, supply chain partners should consider unique blended strategies that are beyond their individual firms, and these strategies should be applied in their decision-making. The results show that the demands and orders in majority of Halal food companies are planned with the collaboration 
of most partners. Some of their processes may need changes because they do not possess the required experiences. The organizational learning theory of SCM suggests that these companies can use the knowledge of their supply chain partners in managing these processes.

Figure 4. Mean score of LSC practices.

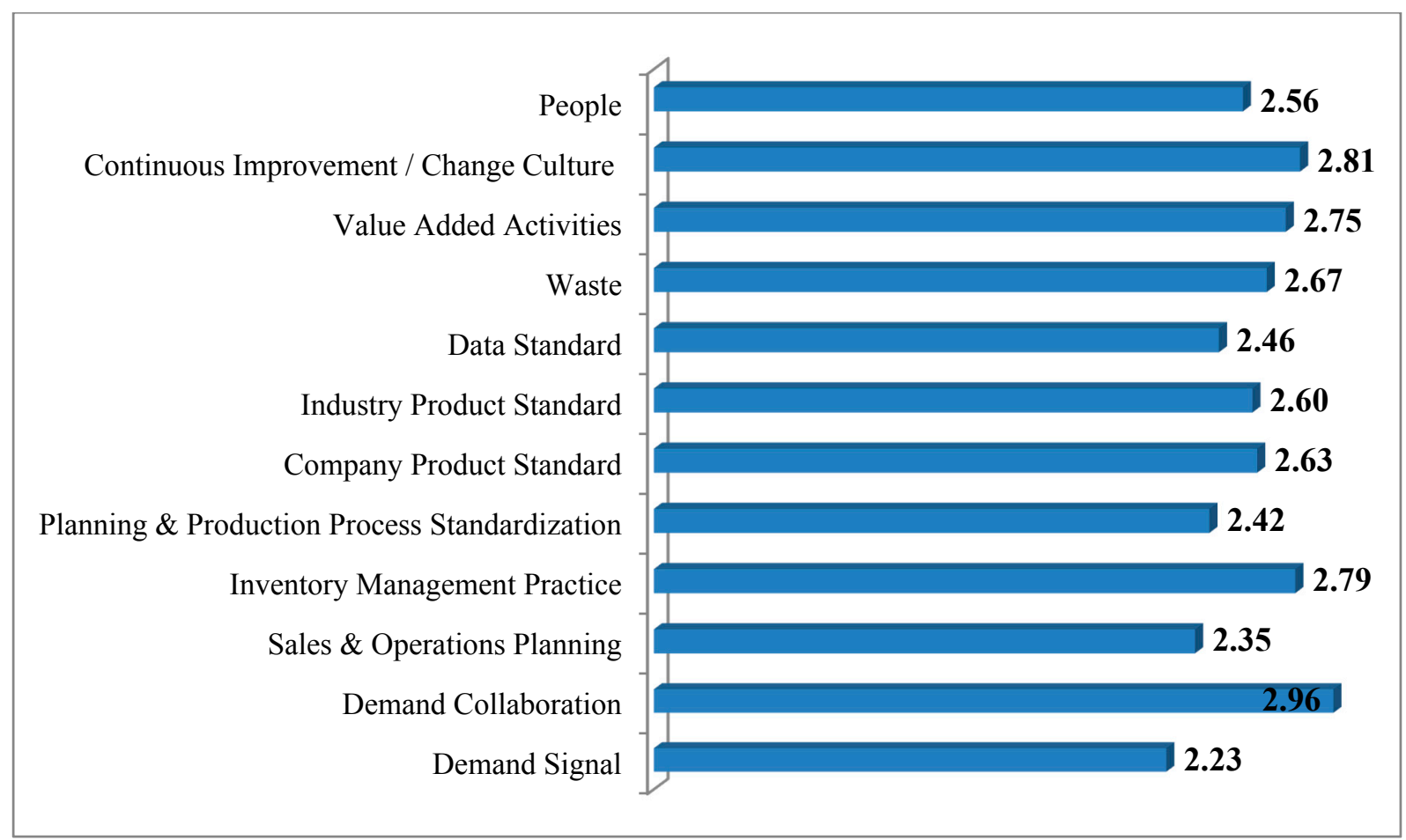

Table 8. Rate (\%) of LSC practices implementation.

\begin{tabular}{lcccc}
\hline Item & A & B & C & D \\
\hline Demand Signal & 18.8 & 54.2 & 12.5 & 14.6 \\
Demand Collaboration & 10.4 & 25.0 & 22.9 & 41.7 \\
Sales and Operations Planning & 29.2 & 33.3 & 10.4 & 27.1 \\
Inventory Management Practice & 14.6 & 33.3 & 10.4 & 41.7 \\
Planning and Production Process Standardization & 14.6 & 54.2 & 6.3 & 25.0 \\
Company Product Standard & 16.7 & 35.4 & 16.7 & 31.3 \\
Industry Product Standard & 18.8 & 37.5 & 8.3 & 35.4 \\
Data Standard & 22.9 & 35.4 & 14.6 & 27.1 \\
Waste & 14.6 & 39.6 & 10.4 & 35.4 \\
Value-Added Activities & 14.6 & 35.4 & 10.4 & 39.6 \\
Continuous improvement & 14.6 & 27.1 & 20.8 & 37.5 \\
People & 22.9 & 33.3 & 8.3 & 35.4 \\
\hline
\end{tabular}

The second important practice of LSC implementation is continuous improvement, which obtained a mean score of 2.81 (Figure 4). About $37.5 \%$ of the companies have fully implemented this practice. Their management has well-developed published visions for all facilities and operating objectives that fully support the vision. A continuous improvement culture exists across the entire supply chain. About $20.8 \%$ of the companies that are implementing continuous improvement practice stated that their leaders have been identified at the operational level change and are being educated on the need to change and 
how to effect change. These companies do not fully implement this practice, but are at the high stage of adaption. About $27.1 \%$ of the companies are at the first stage of implementation and have recently focused on informal improvement projects. By contrast, $14.6 \%$ of the companies have no existing implementation and any continuous improvement program. The high level of adoption of continuous improvement practice is a very important tool in LSC implementation. Implementing a continuous improvement program in the entire supply chain cannot be accomplished unless all partners join in the problem solving and sharing of goals, experiences, information, and values. The first step is anchored in game theory, where these companies create a trustworthy relationship and mutual relation to pursue supply advantages. Next, these companies participate in joint problem solving and knowledge sharing. Companies with limited experiences are expected to learn from their strong partners in terms of managing activities more effectively.

Inventory management is the third important practice in LSC implementation because it is directly related to demand management across the supply chain. These supply chains are expected to be successful in managing their inventory because they highly implement demand collaboration. They can receive the required and reliable demand information of their partners, which is needed for managing their inventory. Several companies $(41.7 \%)$ stated that their supply chain partners have implemented inventory visibility systems and processes to reduce excess inventory throughout the supply chain. Sharing of inventory data suggests the existence of a trustworthy relationship across supply chains to obtain the advantages. Hence, supply chains do not only reduce inventory process and associated costs, but they also allow products to be produced and delivered in the right time, at the right place, and with right quality and quantity. Most companies are adapting inventory management programs. However, the remaining companies are yet to commence implementation. Only $10.4 \%$ of the companies reported that their supply chain partners jointly consider lead-time reductions and postponement strategies, which indicate a satisfactory level of inventory management. By contrast, 33.3\% of the companies stated that their inventory is managed independently and their focus is on the cost of the total purchase. The rest of the companies $(14.6 \%)$ do not consider inventory management in their strategy plan. These companies only focus on unit price without considering total cost (carrying costs, transportation, etc.). These companies do not respect the benefits of the entire supply chain and solely focus on their individual benefits. The strategic choice and game theories of SCM suggest that the lack of trustworthy relationship prevents these companies from making a strong bond in managing their activities. Inventory is not an easy process because it is dependent on management, design, production, and distribution activities. The design department must prepare 2D and 3D drawings to crate tools and molds on time. The transportation system must send semi-processed products on time to feed the production line, which is expected to produce the product on time. Therefore, inventory management requires a strong bond among suppliers and customers to send and to receive information and products on time.

The implementation of value-added activities is the fourth important practice in LSC implementation (Figure 4). The results show that $37.5 \%$ of Halal food companies fully implement this practice. Collaborative practices are actively being performed between suppliers and customers to eliminate non-value-added activities. However, $20.8 \%$ of Halal food companies reported that the collaborative practices being explored with their suppliers and customers are not yet fully implemented. About $27.1 \%$ of these companies are aware of the value-added, but they have not actively worked to eliminate non-value-added activities. About $14.6 \%$ of the companies do not have a clear distinction between value-added and 
non-value-added activities. Thus, more than half of the Halal food companies collaborate with their partners to eliminate non-value-added activities. This approach shows a high level of implementation and understanding of this tool. A high percentage of Halal food companies are expected to succeed in managing their activities, which include demand, design, production, storage, distribution, and human resource, because these companies are collaborating with their supply chain partners to eliminate non-value-added activities. The results of this study meet this expectation and show a high level of demand collaboration, improved storage, continuous improvement, waste reduction, production cooperation, and human resource improvement (Table 8).

Waste reduction, which has a mean score of 2.67, is the fifth important tool in LSC implementation (Figure 4). Some Halal food companies (35.4\%) reported that their supply chain partners understand the end-to-end processes and work together to eliminate wastes throughout the supply chain. This collaboration indicates that these companies have a high level of waste reduction implementation. By contrast, a small percentage of Halal food companies (14.6\%) stated that waste reduction only focused on functional areas within their company. These companies have no internal processes or collaboration among their supply partners to reduce waste. The rest of the companies are in the process of minimizing wastes in their internal activities and the entire supply chain (Table 8). These results indicate a good level of awareness of basic concept of LPs among Halal food companies (wastes reduction). These companies are expected to implement LSC practices fully and successfully.

Company and industry product standard is the sixth important tool of LSC implementation (Figure 4). New products were developed based on existing products of the internal production line among more than $31 \%$ of these companies as well as on the production line of their partners. This strategy reduces the risk of encountering problems in design, production, storage, packaging, and distribution processes. This strategy can eliminate waste, and save time, money, and human resources. Companies can achieve various benefits from sharing standard products in their supply chain. However, less than 19\% (Table 8) of Halal food companies do not use standard products in their production line, which can be attributed to their lack of awareness of the benefits of product sharing or the lack of collaboration and trust among supply chain partners.

Human resource is the seventh important practice in LSC implementation (mean score 2.56; Figure 4). Employees from $35.4 \%$ of these companies believe they are valuable assets. They believe that strategic decisions were made based on the benefits of the employees, and they are involved in the implementation of new systems such as LSC. About $8.8 \%$ of the companies allocate resources for employee development. However, more than $50 \%$ of Halal food companies do not pay considerable attention to its employees. Managers are concerned about their employees, but limited institutional support or resources are allocated to them. These results explain the reason why Halal food companies are not completely successful in implementing LSC. The implementation of each new system is highly dependent on the workers who are directly or indirectly involved in its implementation. Therefore, lack of employee satisfaction may cause new system adoption to fail.

The use of standard data is another important practice of LSC implementation. Information sharing is one of the most important issues in supply chain management [81]. Every part of the supply chain is deeply influenced by information. Daily operational decisions are made at each stage of the supply chain according to the available information. Thus, the use of global or industry standard data can facilitate information sharing among supply chain partners. However, some Halal food companies (27.1\%) use 
global or industry standard data format to exchange product availability and sales-related data. About $22.9 \%$ of these companies do not share information with their partners. Therefore, these chains may face issues related to the management of production, inventory, and distribution systems. The lack of trustworthy relationship and top management support, financial problems, and lack of appropriate IT infrastructure are the most important reasons behind this matter.

Planning and production process standardization (Figure 4) has a low mean score (2.42) compared with other LSC tools, which indicates that this tool is less important. About $14.6 \%$ of Halal food companies did not attempt to standardize their processes internally or across the supply chain. Majority of these companies (54.2\%) standardized their internal processes, but they did not share these standards with their supply chain partners. Only $25 \%$ of the participants have fully implemented this practice. These companies defined their planning, production, and stock management processes and standardized these processes across the supply chain.

POS data are important information that can be shared across the supply chain to decrease demand variation and order fluctuation. The supplier can produce superior inventory management and demand predictions by receiving relevant POS information. A company can also gain competitive edge because the POS information of competing products can be tracked to improve the sales strategy for its own products. POS data sharing shows the amount of gross product and clarifies local demand patterns, costs, and promotion schedules [82]. Despite these benefits, majority of Malaysian Halal food companies do implement sales and operations planning for sharing POS data. Only $27.1 \%$ of these companies have sales and operations planning, which uses on-line tools that are available to the supply chain partner. The low percentage of sales data sharing reveals that these companies are not aware of the advantages of using this data or they do not trust their partners with the information.

Demand collaboration is the most important practice in LSC implementation. However, demand signal is afforded with the lowest attention (Figure 4), which is attributed to lack of appropriate forecasting system. Most companies (54.2\%) forecast their demand based on actual product usage (current stock levels, $\mathrm{min} / \mathrm{max}$ levels, or order points) and projected sales. Only $14.6 \%$ of the companies reported that their products are pulled from the channel using consumer demand from POS systems in real time. Thus, the lack of sales and operations planning practice causes difficulty in implementing demand signal practices.

Manzouri et al. [83] conducted a similar study among Malaysian Halal food companies to examine their lean manufacturing (LM) practices adoption. These results indicate that most work was conducted in human resources, which was focused on worker training. However, supplier and customer relationship practices, which include information sharing and supplier and customer involvement in management of activities, were at the lowest level. These results indicate the reasons that they did not succeed in LSC implementation. The lack of supplier-customer collaboration in fulfilling relevant activities causes difficulties in supply chain management either in material flow or information sharing. These companies pursue individual benefits instead of supply advantages. The game theory of SCM suggests the importance of a trustworthy and mutual relationship among supply chain partners to facilitate the risk and reward sharing and to avoid individual activities. 


\section{Conclusions}

These results show that the important tools of LSC implementation include demand collaboration, continuous improvement, inventory management practices, value-added activities, waste reduction, company and industry standard, human resource, data standard, planning and production process standardization, sales and operations planning, and demand signal. However, most companies aim for the full implementation of demand collaboration, inventory management, and value-added activities tools at the highest rate, which indicates the importance of adapting these activities across the supply chain. First-stage adoption partners must jointly participate in demand analysis before the implementation of visibility systems and processes for inventory. Collaborative practices must be actively performed at all stages of LSC adoption. Companies have little interest in adopting sales and operations planning activities across the whole supply chain. Most companies intend to develop their sales and operation planning individually. Companies should utilize POS data and implement this practice across the entire supply chain because of the benefits of information sharing and use of POS data.

This study shows that Malaysian Halal food companies do not succeed in the adoption of LSC practices. These companies manage their activities individually regardless of supply chain benefits. These findings indicate the unfamiliarity of these companies with the concept of lean adaption and their lack of full understanding of the goal of supply chain. Human resources, which include worker training, employee involvement in LSC implementation, team decision-making, and cross-functional teams, are not important practices in LSC implementation. Thus, the lack of quality system adoption in some companies can be attributed to human resources. The appropriate treatment of workers encourages them to participate in the adoption of new systems to avoid system failure. Proper forecasting systems for demand management are not deployed and are mostly focused on pushed systems instead of pulling systems. Less attention is afforded to the use of standard data, which causes serious issues, especially in information sharing. Most of these companies do not have a comprehensive system for the development of standard products, which can help them decrease human error and risk of failure during design, molding, production, and packaging. However, continuous improvement systems have gained considerable attention from these companies. Thus, this tool is expected to overcome various issues. However, the results did not meet this expectation and showed several shortcomings. Therefore, these supply chains were not fully successful in its implementation despite the existence of a continuous improvement culture. These supply chains must expand their decision-making and practices.

Some findings of the study require further research. First, the effect of LSC implementation tools and techniques on the improvement of company performance can be further studied. Another area that requires further exploration is the examination of barriers to the implementation of LSC practices and the possibility of recovering these issues. The sample used in this study consisted of respondents from Halal food industries in Malaysia. Future researchers may conduct a similar study not only in Malaysian industries but also in other Islamic countries.

\section{Recommendations for Halal Food Companies}

Since the study indicates lack of LSC practices adoption among Halal food companies, the paper suggests some steps to help them in implementing these practices more successfully. The first step is to 
understand the ultimate goal of LSC via benchmarking from leading LSC companies and participating in training courses. In this stage understanding LSC concepts, implementation, requirements, barriers and benefits by top managers indicate the critical role, since they will supervise all changes in future.

In the next step these companies need to change their point of view from seeking individual benefits to the whole supply chain interests. In this regard, conducting meeting with supply chain's members to share their common interests can be a good start. Involving all workers in implementing LSC is the next stage. These companies need to conduct training courses for all employees, consider team decisionmaking and cross-functional teams in managing and implementing LSC practices. These efforts make all employees feel responsible and involve in adopting these practices, which avoids system failure. Afterwards, these companies need to implement a proper IT infrastructure to manage their information systems. This system helps them to forecast their demands, to develop standard products, and decrease human error (in design, molding, production, and packaging). At the final stage they should apply continues improvement systems.

In implementing and applying all these practices government has critical role. Documenting all related experiences of LSC companies is an important part of this role. It would be a fundamental step to add these experiences in MS 1500:2009 standard, which helps other companies to follow standard steps. Conducting LSC training course by some government affiliated agency (such as Jabatan Kemajuan Islam Malaysia (JAKIM) and Jabatan Agama Islam Negeri (JAIN) in Malaysia) make it possible for all companies to access reliable training resources. Moreover, government can assign some sort of awards for those companies that make best efforts to apply LSC practices and are successful. In addition to these awards, government can allocate some kind of financial

\section{Acknowledgments}

The authors would like to thank an editor and three anonymous referees for their constructive comments and suggestions. This work is supported by the University National Malaysia programs (UKM-GUP-2011-053; Integrating the Value of Lean and Green Supply Chain Practice in Halal Manufacturing Sectors, PHI-2014-002; Knowledge Transfer Programme-KTP Grant and Nurturing SMEs through the application of SME-on-STAT as a Green ICT Tool for Quality and Productivity Improvement).

\section{Author Contributions}

Manzouri and Ab-Rahman mostly contributed equally at designing questionnaire and data collection. Halal sections were supervised by Che Mohd Zain and Jamsari. Manzouri analyzes the data and writes the paper. Ab-Rahman provides all required fund and materials. All authors read and approved the final manuscript.

\section{Conflicts of Interest}

The author declares no conflicts of interest. 


\section{References}

1. Demeter, K.; Matyusz, Z. The impact of lean practices on inventory turnover. Int. J. Prod. Econ. 2011, 133, 154-163.

2. Shah, R.; Ward, P.T. Defining and developing measures of lean production. J. Oper. Manag. 2007, 25, 785-805.

3. Pal, A.; Kachhwaha, S.S. Waste cooking oil: A promising feedstock for biodiesel production through power ultrasound and hydrodynamic cavitation. J. Sci. Ind. Res. 2013, 72, 387-392.

4. Sang, L.C.; Khairuzzaman, W.I.W.; Abdul, R.S.Z.; Boon, H.K.;Yew, J.L. Sustaining customers' loyalty: A survey of a coating resins manufacturer. J. Sci. Ind. Res. 2013, 72, 731-734.

5. Kannan, G.; Selladurai, D.V.; Karthi, S. Swaging process for productivity improvement in the manufacture of spindles. J. Sci. Ind. Res. 2013, 72, 681-684.

6. Shah, R.; Ward, P.T. Lean manufacturing: Context, practice bundles and performance. J. Oper. Manag. 2003, 21, 129-149.

7. Cudney, E.; Elrod, C. A comparative analysis of integrating lean concepts into supply chain management in manufacturing and service industries. Int. J. Lean Six Sigma 2011, 2, 5-22.

8. Cua, K.O.; McKone, K.E.; Schroeder, R.G. Relationships between implementation of tqm, jit, and tpm and manufacturing performance. J. Oper. Manag. 2001, 19, 675-694.

9. Corbett, C.J.; Klassen, R.D. Extending the horizons: Environmental excellence as key to improving operations. Manuf. Service Oper. Manag. 2006, 8, 5-22.

10. Nordin, N.; Deros, B.M.; Wahab, D.A.; Ab-Rahman, M.N. Organisational change framework for lean manufacturing implementation. In Proceedings of the 15th International Conference of ISO and TQM, Kajang, Malaysia, 26-28 July 2011.

11. Temporal, P. Brand strategy and implementation for sme companies. In A Seminar on the Strategic Branding of the Halal Industry for Malaysia; HDC: Kuala Lumpur, Malaysia, 2012.

12. Wee, H.M.; Wu, S. Lean supply chain and its effect on product cost and quality: A case study on ford motor company. Supply Chain Manag. Int. J. 2009, 14, 335-341.

13. Marshall, R.E.; Farahbakhsh, K. Systems approaches to integrated solid waste management in developing countries. Waste Manag. 2013, 33, 988-1003.

14. Conti, R.; Angelis, J.; Cooper, C.; Faragher, B.; Gill, C. The effects of lean production on worker job stress. Int. J. Oper. Prod. Manag. Decis. 2006, 26, 1013-1038.

15. Arlbjørn, J.T.; Freytag, P.V.; Haas, H. Service supply chain management: A survey of lean application in the municipal sector. J. Phys. Distrib. Logist. Manag. 2011, 41, 277-295.

16. Choi, B.; Kim, J.; Leem, B.; Lee, C.Y.; Hong, H.K. Empirical analysis of the relationship between six sigma management activities and corporate competitiveness: Focusing on samsung group in korea. Int. J. Oper. Prod. Manag. 2012, 32, 528-550.

17. Womack, J.P.; Jones, D.T.; Roos, D. The Machine that Changed the World, Rawson Associates; Wiley: New York, NY, USA, 1990.

18. Parthan, S.R.; Milke, M.W.; Wilson, D.C.; Cocks, J.H. Cost estimation for solid waste management in industrialising regions-precedents, problems and prospects. Waste Manag. 2012, 32, 584-594.

19. Guerrero, L.A.; Maas, G.; Hogland, W. Solid waste management challenges for cities in developing countries. Waste Manag. 2013, 33, 220-232. 
20. Womack, J.P.; Jones, D.T.; Roos, D. The Machine that Changed the World: The Triumph of Lean Production; Rawson Macmillan: New York, NY, USA, 1990.

21. Lehtinen, U.; Torkko, M. The lean concept in the food industry: A case study of contract a manufacturer. J. Food Distrib. Res. 2005, 36, 57-67.

22. Schonberger, R.J. Japanese production management: An evolution with mixed success. J. Oper. Manag. 2007, 25, 403-419.

23. Scherrer-Rathje, M.; Boyle, T.A.; Deflorin, P. Lean, take two! Reflections from the second attempt at lean implementation. Bus. Horiz. 2009, 52, 79-88.

24. Flott, L.W. Industry in transition. Met. Finish. 2002, 100, 77-82.

25. Srinivasaraghavan, J.; Allada, V. Application of mahalanobis distance as a lean assessment metric. Int. J. Adv. Manuf. Technol. 2006, 29, 1159-1168.

26. Pavnaskar, S.J.; Gershenson, J.K.; Jambekar, A.B. Classification scheme for lean manufacturing tools. Int. J. Prod. Res. 2003, 41, 3075-3090.

27. Olsen, E.O. Lean Manufacturing Management: The Relationship between Practice and Firm Level Financial Performance. Ph.D. Thesis, Ohio State University, Columbus, OH, USA, 2004.

28. Herron, C.; Braiden, P.M. A methodology for developing sustainable quantifiable productivity improvement in manufacturing companies. Int. J. Prod. Econ. 2006, 104, 143-153.

29. Liker, J.K.; Meier, D. The Toyota Way Fieldbook; McGraw-Hill: New York, NY, USA, 2005.

30. Alamgir, M.; Bidlingmaier, W.; Cossu, R. Successful waste management strategies in developing countries require meaningful involvement of the concerned stakeholders. Waste Manag. 2012, 32, 2007-2008.

31. Panizzolo, R. Applying the lessons learned from 27 lean manufacturers. The relevance of relationships management. Int. J. Prod. Econ. 1998, 55, 223-240.

32. Melton, T. The benefits of lean manufacturing: What lean thinking has to offer the process industries. Chem. Eng. Res. Des. 2005, 83, 662-673.

33. Motwani, J. A business process change framework for examining lean manufacturing: A case study. Ind. Manag. Data Syst. 2003, 103, 339-346.

34. Simboli, A.; Taddeo, R.; Morgante, A. Value and Wastes in Manufacturing.: An Overview and a New Perspective Based on Eco- Efficiency. Adm. Sci. 2014, 4, 173-191.

35. Russell, R.; Taylor, B. Operation Management: Quality and Competitiveness in a Global Environment; Wiley: New Jersey, NJ, USA, 2006.

36. Plenert, G. Reinventing Lean: Introducing Lean Management into the Supply Chain; Linacre House, Jordan Hill: Oxford, UK, 2007.

37. Phelps, T.; Hoenes, T.; Smith, M. Developing Lean Supply Chain: A Guidebook; Altarum Institite: Ann Arbor, MI, USA, 2003.

38. Ohno, T. Toyota Production System; Productivity Press: Portland, OR, USA, 1988.

39. Seth, D.; Seth, N.; Goel, D. Application of value steam mapping (vsm) for minimization of wastes in the processing side of supply chain of cottoneseed oil industry in indian context. J. Manuf. Technol. Manag. 2007, 19, 529-550.

40. Mohammed, I.R.; Shankar, R.; Banwet, D.K. Creating flex-lean-agil value chain by outsourcing: An ism-based interventional roadmap. Bus. Process Manag. J. 2008, 14, 338-389. 
41. Srinivasan, M. Streamlined: 14 Principles for Building and Managing the Lean Supply Chain; Thompson: Madison, OH, USA, 2004.

42. MaKee, R.; Ross, D. A framework for auditing and enhancing performanve measurment system. Int. J. Oper. Prod. Manag. 2005, 20, 520-533.

43. Nightingale, D. Lean Supply Chain Management Principles and Practices; Massachusetts Institute of Technology: Cambridge, MA, USA, 2005.

44. Balle, M. Lean attitute-lean application often fail to deliver the expected benefits but could the missing link for successful implementations be attitude? Manuf. Eng. 2005, 84, 14-19.

45. Papadopoulou, T.C.; Ozbayrak, M. Leaness: Experiences from the journey to date. J. Manuf. Technol. Manag. 2005, 16, 784-807.

46. Paul, J.G.; Arce-Jaque, J.; Ravena, N.; Villamor, S.P. Integration of the informal sector into municipal solid waste management in the philippines_-What does it need? Waste Manag. 2012, 32, 2018-2028.

47. Lee-Mortimer, A. A continuing lean journey: An electronic manufacturer's adopting of kanban. Assem. Autom. 2008, 28, 103-112.

48. Wong, Y.C.; Wong, K.Y.; Ali, A. A study on lean manufacturing implementation in the malaysian electrical and electronics industry. Eur. J. Sci. Res. 2009, 38, 521-535.

49. Bhasin, S. Improving performance through lean. Int. J. Manag. Sci. Eng. Manag. 2011, 6, $23-36$.

50. Herron, C.; Braiden, P.M. Defining the Foundation of Lean Manufacturing in the Context of Its Origins (Japan). In Proceedings of the IET International Conference on Agile Manufacturing: Durham, UK, 9-11 July 2007; pp. 148-157.

51. James, T. Wholeness as well leanness. IET Manuf. Eng. 2006, 85, 14-17.

52. Achanga, P.; Shehab, E.; Roy, R.; Nelder, G. Critical success factors for lean implementation within smes. J. Manuf. Technol. Manag. 2006, 17, 460-471.

53. Bonavia, T.; Marin, J.A. An empirical study of lean production in the ceramic tile industry in spain. Int. J. Oper. Prod. Manag. 2006, 26, 505-531.

54. Real, R.; Pralus, M.; Pillet, M.; Guizzi, L. In A Study of Supporting Programs for Small and Medium Enterprises: A First Stage Going to "Lean", Proceedings of the IEEE International Conference on Industrial Engineering and Engineering Management, Singapore, 29 July-1 August 2007; IEEE: Singapore, Singapore, 2007; pp. 515-519.

55. Bleck, D.; Wettberg, W. Waste collection in developing countries - tackling occupational safety and health hazards at their source. Waste Manag. 2012, 32, 2009-2017.

56. De Brandao, S.L.; Michael, P. Exploring the barriers to lean health care implementation. Public Money Manag. 2011, 31, 59-66.

57. Worley, J.M.; Doolen, T.L. The role of communication and management support in a lean manufacturing implementation. Manag. Decis. 2006, 44, 228-245.

58. Al-Sudairi, A.A. Evaluating the effect of construction process characteristics to the applicability of lean principles. Constr. Innov. 2007, 7, 99-121.

59. Lian, Y.H.; Van Landeghem, H. Analyzing the effects of lean manufacturing using a value stream mapping-based simulation generator. Int. J. Prod. Res. 2007, 45, 3037-3058. 
60. Zheng, L.; Xiao, J.; Hou, F.; Feng, W.; Li, N. Cycle time reduction in assembly and test manufacturing factories: A kpi driven methodology. In Proceedings of the IEEE International Conference on Industrial Engineering and Engineering Management, Singapore, Singapore, 8-11 December 2008.

61. Domingo, R.; Alvarez, R.; Pena, M.M.; Calvo, R. Materials flow improvement in a lean assembly line: A case study. Assembly Autom. 2007, 27, 141-147.

62. Grewal, C.S. An initiative to implement lean manufacturing using value stream mapping in a small company. Int. J. Manuf. Tech. Manag. Decis. 2008, 15, 404-417.

63. Seth, D.; Seth, N.; Goel, D. Application of value stream mapping (vsm) for minimization of wastes in the processing side of supply chain of cottonseed oil industry in indian context. J. Manuf. Tech. Manag. 2008, 19, 529-550.

64. Golnaz, R.; Zainalabidin, M.; Mad Nasir, S.; Eddie, C.F.C. Non-muslims' awareness of halal principles and related food products in malaysia. Int. Food Res. J. 2010, 17, 667-674.

65. HDC. Halal standards. Available online: http:/www.Hdcglobal.Com/publisher/gw_halal_ standards (accessed on 25 October 2012).

66. Shafie, S.; Nor, O. Halal certification: An international marketing issues and challenges. Int. Market. Service 2011, 13, 1234-1238.

67. Muhammad, R. Branding halal food as safe,healthy and clean. Halal J. 2007, 27, 141-147.

68. Maheran, N.M.N.; Fizah Md Isa; Kifli, B.C. Positioning malaysia as halal-hub integration role of supply chain sterategy and halal assurance system. Asian Social Science 2009, doi:10.5539/ass.v5n7p44.

69. Sombatsompop, K.; Songpim, A.; Reabroi, S.; Inkong-ngam, P. A Comparative study of sequencing batch reactor and movingbed sequencing batch reactor for piggery wastewater treatment. Maejo Int. J. Sci. Technol. 2011, 5, 191-203.

70. Do, K.-U.; Ha, N.T.T.; Banu, R.; Kim, K.; Heo, J.; Yeom, I.-T. Effects of thermochemical pretreatment on the biodegradability of sludge from a biological wastewater treatment system. Maejo Int. J. Sci. Technol. 2010, 4, 250-260.

71. Sarkis, J.; Zhu, Q.; Lai, K. An organizational theoretic review of green supply chain management literature. Int. J. Prod. Econ. 2011, 130, 131-115.

72. Ketchen, J.D.; Hult, T.M. Bridging organization theory and supply chain management: The case of best value supply chains. J. Oper. Manag. 2007, 25, 573-580.

73. Hitt, M.A. Relevance of strategic management theory and research for supply chain. J. Supply Chain Manag. 2011, 47, 9-13.

74. Saithep, N.; Dheeranupatana, S.; Sumrit, P.; Jeerat, S.; Boonchalearmkit, S.; Wongsanoon, J.; Jatisatienr, C. Composting of tobacco plant waste by manual turning and forced aeration system. Maejo Int. J. Sci. Technol. 2009, 3, 248-260

75. Arbuckle, J. Amos 16.0 User's Guide; Amos Development Corporation: Chicago, IL, USA, 2007.

76. Meehan, J.; Muir, L. Scm in merseyside smes: Benefits and barriers. TQM J. 2008, 20, 223-232.

77. Johnston, D.; McCutcheon, D.M.; Stuart, F.I.; Kerwood, H. Effect of supplier trust on performance of cooperative supplier relationship. J. Oper. Manag. 2004, 22, 23-38.

78. Malhotra, N.K. Marketing Research: An Applied Orientation; Prentice Hall: Englewood Cliffs, NJ, USA, 2007. 
79. Karimikia, H. Impact of it strategy on business strategy in small malaysian enterprises. In Proceedings of the International Conference on Economics, Business and Marketing Management, Singapore, Singapore, 26-28 February 2012.

80. Ab-Rahman, M.N.; Tannock, J. Emergence of quality management within smes in malaysia: Perspective and evidence. Asian J. Manag. 2007, 13, 42-54.

81. Manzouri, M.; Ab-Rahman, M.N.; Arshad, H. Order management in supply chain: A case study in automotive companies. Am. J. Eng. Appl. Sci. 2011, 4, 372-379.

82. Lin, F.; Huang, S.; Lin, Sh. C. Effects of information sharing on supply chain performance in electronic commerce. IEEE Trans. Eng. Manag. 2002, 49, 258-268.

83. Manzouri, M.; Zain, C.R.C.M.; Ab-Rahman, M.N. Lean manufacturing tools in the halal food industries. Int. J. Bus. Manag. 2012, 1, 1-5.

(C) 2014 by the authors; licensee MDPI, Basel, Switzerland. This article is an open access article distributed under the terms and conditions of the Creative Commons Attribution license (http://creativecommons.org/licenses/by/4.0/). 